\title{
O lugar nos estudos toponímicos: reflexões
}

\section{Place in toponymic studies: reflections}

\author{
Karylleila Santos Andrade \\ Universidade Federal do Tocantins \\ karylleila@gmail.com
}

Resumo: Este texto parte da seguinte questão norteadora: qual é a posição ou status que lugar ocupa nos estudos toponímicos? O objetivo geral é discutir lugar como categoria na disciplina toponímia para, em seguida, propor seu alargamento conceptual. Utilizar-se-á a abordagem teórica da Geografia Cultural e Humanista, a partir do viés da Fenomenologia, como também, os princípios teórico-metodológicos da disciplina Toponímia. É uma pesquisa de cunho qualitativa e interpretativista. Conclui-se, nesta etapa do trabalho, que lugar pode ser interpretado como categoria, pois trata-se da extensão/apreensão das relações (motivações) as quais são estabelecidas entre o homem e o próprio nome de lugar: é a sua gênese. $\mathrm{O}$ alçamento, enquanto categoria central, deu-se com uma discussão prévia das categorias espaço, território, paisagem e lugar. Daí o conceito em uma dimensão analítica: motivacional, histórica, linguística, ideológica, social, identitária. Quanto à sua extensão semântica, essa acontece no plano da abstração do vínculo que se estabelece entre o denominador e o designatum: como sentimento de pertencimento, afetividade, mundo vivido e experienciado.

Palavras-chave: lugar; categoria; toponímia; geografia cultural e humanista.

Abstract: This paper stems from the following guiding question: what is the position or status that place occupies in toponymic studies? The overall objective is to discuss place as a category in toponymic 
studies and, then, to propose an extension for its concept. We will use the theoretical approach of Cultural and Humanistic Geography, from the the point of view of Phenomenology, and also the theoretical and methodological principles of Toponymy as a discipline. It is a research of qualitative and interpretative nature. It can be concluded, at this stage of the work, that place can be interpreted as a category because it is the extension/seizure of relations (motivation) that are established between man and the place name itself: it is its genesis. Its rising, as a nuclear category, was achieved after prior discussion of space, territory, landscape and place categories. Hence the concept in an analytical dimension: motivational, historical, linguistic, ideological, social, identitary. As for its semantic extension, this happens in the abstraction plan of the bond that is established between the denominator and the designatum: as sense of belonging, affection, world lived and experienced.

Keywords: place; category; toponymy; cultural and humanistic geography.

Recebido em: 06 de outubro de 2015

Aprovado em : 01 de junho de 2016

\section{Introdução}

Ao se estudar o léxico de uma língua, pode-se também apreender a realidade do grupo que a utiliza: cultura, história, modo de vida e visão de mundo. As palavras que constituem o sistema lexical de uma língua são como um espelho: refletem os aspectos do mundo concreto em uma realidade. Segundo Andrade (2010, p. 106), o ser humano, ao utilizar-se do léxico, sempre atribui nome a tudo que o cerca: às coisas, aos animais, às pessoas, ao espaço físico e cultural em que vive. Nomear é, para o homem, uma necessidade de organização e de orientação.

É no plano da denominação que o topônimo surge como o resultado da ação do nomeador ao realizar um recorte no plano das significações, representações, ou seja, praticar um papel de registro no momento vivido pela comunidade. É nessa etapa, portanto, que compreendemos que, no ato de denominar a coisa, o recorte cultural apreendido, estabelece-se um vínculo de afetividade com a coisa nominada, o lugar, corporificado e materializado. 
Sabemos que o signo toponímico é motivado, sobretudo, pelas características físicas do local ou pelas impressões, crenças e sentimentos do denominador. Além de diferir dos demais signos no que se refere à motivação, tem particularidade específica quanto à função. $\mathrm{O}$ signo linguístico se reserva à arbitrariedade, enquanto o signo toponímico à motivação. $\mathrm{O}$ que os diferencia é a função significativa quando a Toponímia os transforma em seu objeto de estudo.

$\mathrm{Na}$ atividade onomasiológica, Todorov (1983, p. 37-38) faz referência à atividade de nomeação de Colombo, durante o descobrimento da América. Em matéria de linguagem, Colombo faz menção aos nomes próprios e diz que, em certos aspectos, são os que mais se assemelham aos indícios naturais. A sua preocupação se inicia pelo próprio antropotopônimo Colombo. Ele modificou a grafia de seu nome várias vezes, tentou chamar-se Colón, recuperando um nome antigo, motivado pela vontade divina que o havia "eleito" para realizar o que seu nome e sobrenome significavam. Desse modo, por diversos motivos, feito o recorte, a apreensão no espaço, o lugar recebe o batismo, a "benção", afere-se alma, "“nome" e "lugar" constituem-se uma unidade identitária, referencializada e referenciável (DICK, 2008, p. 179)".

É fato que nome e lugar constituem uma unidade identitária, que marca o recorte cultural. Particularmente, entendemos essa unidade (nome e lugar) como um sentimento de ligação, de alma, de afetividade. Sabemos que a Toponímia é o estudo dos nomes de lugares, mas uma inquietação tem nos tomado como desafio quando pensamos na noção de lugar, já que o nome é o significante. Esse, sim, passa a ter alma quando relacionado com o lugar. Mas o que é o lugar em Toponímia? Partindo, então, dessa angústia provocadora, um dos desafios deste trabalho é perceber qual é a posição que lugar ocupa nos estudos toponímicos?

Uma provável resposta, ainda que embrionária, é de que a ideia de se construir um sistema de identificação de categoria na disciplina Toponímia se faz pensando no real: ela reproduz a realidade que se quer abstrair. No nosso entender, lugar torna-se, então, categoria central, pois se trata da extensão/apreensão das relações (motivações) que são estabelecidas entre o homem e o próprio nome de lugar: é a sua gênese. Por isso, é essencial, a priori, conceituar lugar em uma dimensão de categoria analítica: motivacional, histórica, linguística, ideológica, social, identitária. E um diálogo com outras áreas do saber é fundamental, como, por exemplo, a Geografia Cultural e Humanista. 
O trabalho está dividido em 3 (três) partes: a primeira referese à discussão de Lugar como categoria nos estudos toponímicos, a segunda propõe-se discutir Lugar na perspectiva da Geografia Cultural, Humanista e Toponímica, por fim, o subitem Caminhos ainda a trilhar que retoma a questão balizadora inicial do texto se posicionando na extensão conceptual de lugar como categoria nos estudos toponímicos. O nome de lugar é compreendido como patrimônio linguístico e cultural, testemunho de uma comunidade. Materializado e corporificado, o nome é um produto e o reflexo social e cultural da cosmovisão de um grupo.

A pretensão deste estudo não é, de forma alguma, modificar, em sua essência, o conceito de Toponímia como o estudo do nome de lugar. A proposta vincula-se mais na perspectiva de ampliação conceptual do que seja lugar na própria disciplina. A intenção é construir, no primeiro momento, uma proposição conceitual e metodológica que permita alçar lugar à noção de categoria nos estudos toponímicos. Para isso, apoiarnos-emos em questões teóricas da Geografia Cultural e Humanista. Em seguida, apresentamos a correlação dos conceitos debatidos a fim de apresentar, ainda que preliminarmente, uma extensão conceptual de lugar como sentimento de pertencimento, afetividade, mundo vivido e experienciado.

\section{Lugar: almejando uma categoria na Toponímia}

Conhecimento vem do latim cognitio, ação de aprender. Clément et al (1994, p. 69) assinalam que o conhecimento é concebido como uma atividade pela qual o homem toma consciência dos dados da experiência e procura compreendê-los ou explicá-los. Nesse processo, o homem procura adquirir saberes, assimilar conceitos sobre os fenômenos reais, compreender o mundo a sua volta: seu fim consiste em alcançar a verdade objetiva.

São vários os tipos de conhecimento, dentre eles: o senso comum, o religioso, o filosófico e o científico. Este último é o que mais se diferencia dos demais, e uma das razões é a necessidade de uma ordenação em suas proposições, e isso acontece no ato da relação do pensamento humano com os objetos, por meio de definições de conceitos básicos. Estamos denominando esses conceitos básicos de categorias. Segundo Clément e al (1994, p. 55), categoria vem do grego Katègoria de Kategorein, quer dizer "afirmar". Na filosofia, frequentemente, é sinônimo de conceito no 
sentido de noção de classificação, e tem por função selecionar, congregar, enquadrar os seres, as coisas, os pensamentos. Dessa maneira, a categoria pode e deve ser reconhecida como o modo de ser das coisas e nesse caso, as coisas não podem ser pensadas no vazio, não há modo de ser sem o ser.

Então, sendo categorias modos de ser, as mesmas podem representar propriedades gerais dos objetos, ou seja, qualidades objetivas do ser. Caminhando nesse sentido, ao considerarmos a Toponímia como uma disciplina do conhecimento científico, identificamos nela a existência de uma ordenação em suas proposições. Ou seja: a determinação de categorias que relacionem o objeto da Toponímia e o pensamento humano. Nosso interesse, portanto, é estudar, com mais afinco, qual é a extensão do significado de lugar, o qual constitui-se como elemento caracterizador na própria definição da disciplina - estudo do nome de lugar-e que, na nossa concepção, deve ser elevado à noção de categoria.

O conhecimento científico é real porque se apoia em fatos, experimentações, observações, ou seja, utiliza-se de processos de descrições e análises, bem como, reflexões dos fatos. Uma de suas características é a de que se constitui "em um conhecimento falível, em virtude de não ser definitivo, absoluto e final, e, por esse motivo, é aproximadamente exato: novas proposições e o desenvolvimento de técnicas podem reformular o acervo da teoria existente (LAKATOS; MARCONI, 1991, p. 17)". Apoiar-nos-emos nessa perspectiva para pensar o que abrange lugar em Toponímia.

Direcionamos, portanto, nossa investigação para a compreensão e o desvelamento do fenômeno ${ }^{1}$ a ser estudado: qual é a posição que lugar ocupa nos estudos toponímicos? Enfatizamos, assim, a descrição densa e exaustiva do fenômeno e seus sentidos. Conforme Sartre (1997, p. 16), o que o fenômeno é, é absolutamente, pois se revela como é. Pode ser estudado e descrito como tal, porque é absolutamente indicativo de si mesmo. "O fenômeno é o que se manifesta, e o ser manifesta-se a todos

\footnotetext{
${ }^{1}$ Para Clément et al (1994, p. 149), fenómeno vem do grego phainomenon, de phainestai, ser visível, brilhar, de phôs, a luz. Ainda segundo os autores, os filósofos que se dizem da "fenomenologia" estimam que, no fenómeno, são as próprias coisas que se revelam: o projecto fenomenológico consiste precisamente neste esforço no sentido de deixar desvendar-se - a partir da intuição imediata, da experiência concreta - o "mundo" situado aquém da ciência. A "visão das essências" no fenómeno é possível graças ao método fenomenológico, que nos permite restabelecer uma relação originária com as coisas "em carne e osso" (grifos dos autores).
} 
de algum modo, pois dele podemos falar e dele temos certa compreensão" (SARTRE, 1997, p. 19). Isto nos faz pensar que, em geral, o fenômeno é tudo aquilo que se mostra, ou seja, o que aparece com evidencia à percepção dos sentidos ou consciência. Mais do que aparência, é uma realidade concreta ou percebida, identificada.

Quando (nos) interrogamos, focalizamos o fenômeno e não a coisa em si, pois a ideia de fato tem sua gênese nos fundamentos da lógica positivista. E essa lógica concebe o fato como tudo aquilo que pode tornar-se objetivo, explicativo e rigoroso como objeto científico. Teremos, então, ideias como as de causalidade, repetitividade e controle, entre outras. Interrogar implica pensar sobre o que estou me propondo a examinar. É preciso ativar o pré-reflexivo, o qual diz respeito a um assunto, objeto de estudo, que o investigador aspira conhecer, mas que ainda não está bem explicado, claro. Portanto, não se parte do vazio, de algum modo já se conhece de onde quer partir. É a volta às coisas em si mesmas. Boemer (1994, p. 87) diz que "quanto mais o pesquisador conhecer a temática, maior é o seu pré-reflexivo, e isso possibilita-lhe colocar o fenômeno diante dos olhos, em suspensão, e olhar para ele de forma atentiva". No entanto, deve-se evitar que a teoria a ser abordada influencie o seu interrogar a ponto de oferecer-lhe respostas prontas.

Chauí (2002, p. 61), leitora de Merleau-Ponty, assinala que o filósofo procurava as essências - do comportamento e da percepção - embora não em caráter de redução. Como considerava impossível a constituição transcendental como ato do sujeito constituinte, MerleauPonty apud Chauí (2002, p. 61) não trabalhava como a separação noemanoesis (objeto/o pensado - subjetivo/a percepção) e a tese do mundo natural, mas buscava a essência do comportamento e da percepção no interior do fato ou do que ele chamava de existência. Aqui existência é entendida como o modo de ser dos objetos lógicos que se definem pela não contradição. Nos dizeres de Merleau-Ponty, há uma preocupação com a gênese dos sentidos: "a fenomenologia é a descrição e não explicação (científica) e nem análise (reflexiva) [...] (CHAUI, 2002, p. 63)”. Para tanto, esta investigação compreende o estudo do fenômeno do ponto de vista interpretativo e descritivo, de cunho qualitativo.

Os estudos de pesquisa qualitativa diferem entre si quanto ao método, à forma e aos objetivos. Compreendem um conjunto de diferentes técnicas interpretativas que visam a descrever e a decodificar os componentes complexos de significados. "Segundo esta perspectiva, 
um fenômeno pode ser melhor compreendido no contexto em que ocorre e do qual é parte, devendo ser analisado numa perspectiva integrada" (GODOY, 1995, p. 21). Tem por objetivo revelar e expressar o sentido dos fenômenos no mundo social; trata-se de abreviar a distância entre teoria e o corpus; entre o contexto e a ação.

A pesquisa qualitativa, abordada neste estudo, tem como interesse a relação noema-noesis (aquilo que é percebido - ato de perceber/atividade da consciência) a fim de que se possa obter a descrição do contexto e alcançar a compreensão do fenômeno. Embora nossa preocupação tenha como foco o fenômeno em si, sua descrição e interpretação, isso não quer dizer que não possamos partir também para uma explicação dos fatos, tendo em vista seus determinantes e suas relações intrínsecas. Ao partir desse movimento, advém uma transformação que pode gerar uma nova atribuição de significado, ou simplesmente, a ressignificação de sentidos.

Uma das características essenciais capazes de identificar uma pesquisa de cunho qualitativo é o enfoque descritivo e indutivo. O processo indutivo inicia-se pela coleta de dados, que sistematizados permitem, partindo das experiências e observações, chegar a certas inferências ou generalizações. Nesse sentido, intencionamos partir do próprio conceito de Toponímia, estudo dos nomes de lugares, a fim de compreender o status de lugar nesse conceptus. Acreditamos que uma abordagem pelo viés da Geografia Cultural e Humanista nos possibilitará ampliar os horizontes de lugar enquanto categoria analítica.

Lembramos que a Toponímia é capaz de "evidenciar marcas na história social (formação étnica, processos migratórios, sistema de povoamento de uma região administrativa) e perpetuar características do ambiente físico (vegetação, hidrografia, geomorfologia, fauna e outros) de uma região" (ISQUERDO; SEABRA, 2010, p. 79). É fundamental compreender os topônimos a partir dos diferentes significados, olhares e áreas de atuação, pois, por se organizarem de maneira dinâmica, constantemente (re)inventam-se no tempo e no espaço, sobrepondo-se valores socioculturais, econômicos, políticos e religiosos.

Ao procurar discutir um constructo teórico e metodológico para elevar lugar à categoria principal em Toponímia, valemo-nos de que em ciência nada pode ser para sempre. O conhecimento está sempre em movimento, em transformação, e novas proposições podem ser apresentadas, conceitos podem ser revistos ou ampliados, dados podem ser contestados. $\mathrm{O}$ estudo toponímico prevê um diálogo com diversos 
saberes, os quais estão continuamente em mudança: “é uma disciplina que se volta para a História, a Geografia, a Linguística, a Antropologia, a Psicologia Social e, até mesmo, à Zoologia, à Botânica, à Arqueologia, de acordo com a formação intelectual do pesquisador" (DICK, 1990, p. II). Deve ser pensada como um complexo línguo-cultural: um fato do sistema das línguas humanas. Faz parte de uma ciência maior, a Onomástica, a qual se subdivide em Toponímia, estudo do nome de lugar, e Antroponímia, estudo do nome de pessoas. Como explicita Ullmann (1964, p. 161), "o estudo dos nomes próprios ou onomástica pode esclarecer muitos aspectos da história política, econômica e social".

Ao utilizar-se de uma metáfora, o ato de tecer, vislumbramos a complexidade das teias de relações que abarcam o conhecimento como categoria essencial do processo educativo. Segundo ANDRADE (2012, p. 205-206), podemos pensar, então, que a relação da Toponímia, a partir de uma visão interdisciplinar, estabelece o sentido de unidade diante dos diversos saberes. Ou seja: possibilita ao sujeito re/encontrar a identidade, a história, a etimologia do nome na multiplicidade de conhecimentos, tendo em vista, o plano onomasiológico no ato de dar nomes aos lugares. No sentido da construção da teia do conhecimento, a integração das diversas ciências não garante a sua perfeita execução. A interdisciplinaridade, nesse caso, aparece como uma possibilidade de enriquecer e ultrapassar a integração dos elementos do conhecimento.

A episteme ${ }^{2}$ que envolve os estudos toponímicos compreende o estudo das relações (motivações) que são estabelecidas entre o homem e o nome de lugar. É nesse sentido que o estudo dos nomes de lugares sugere um movimento de aglutinação de múltiplos aspectos socio-históricos, culturais, geográficos e linguísticos. Portanto, não deve ser visto como um estudo de saberes partilhados, despedaçados e isolados, apenas sob o enfoque disciplinar. O sujeito (o enunciador, o emissor) tem um papel fundamental na nomeação do lugar. É ele quem estabelece os parâmetros de seleção das motivações, sejam elas de força da natureza ou humana.

Dick (2008, p. 179) ao dizer que nome e lugar constituem-se uma unidade identitária, referencializada e referenciável faz outra observação:

\footnotetext{
2 Epistemologia: do grego epistèmè, "ciência" e logos, "discurso". Utilizado, sobretudo, nos países Anglo-saxónicos, refere-se à análise ou estudo dos processos evolutivos gerais do conhecimento; epistemologia é, neste caso, sinónimo de "teoria do conhecimento" (ou gnoseologia). (CLÉMENTE et al, 1994, p. 119)
} 
"o de lugar e o de não-lugar, que correspondem, contrastivamente, ao nome-dito e ao não nome" (DICK, 2008, p. 179). O lugar refere-se ao ponto do espaço, ao recorte propriamente dito, vincula-se à relação nome/lugar (denominação/referência) de modo transparente, como assevera a investigadora. Em um outro trabalho, a autora coloca que a compreensão da linguagem toponímica se dá também pelo aspecto nãoverbal: o cheiro, as cores, o brilho, a sombra, o olhar. Esses elementos de produção e construção de conteúdos, manifestados na apropriação dos recortes do espaço, são, para Dick (2008a, p. 229), a primeira tentativa de transformação de um não-lugar em lugar, que vai ocorrer no momento em que o denominador se apropria do espírito da denominação no que diz respeito à projeção da referência.

Com base nos apontamentos de Dick (2008 e 2008a), retomemos a pergunta norteadora: qual é a posição que lugar ocupa nos estudos toponímicos?

Uma possível resposta, ainda que incipiente, é que a ideia de se construir um sistema de identificação de categoria na disciplina Toponímia se faz pensando no real: ela reproduz a realidade que se quer abstrair. No nosso entender, lugar torna-se, então, categoria central, pois trata-se da extensão/apreensão da relação (motivações) que são estabelecidas entre o homem e o próprio nome de lugar: é a sua gênese. Por isso, é essencial, a priori, conceituar lugar em uma dimensão de categoria analítica: motivacional, histórica, linguística, ideológica, social, identitária. A sugestão é uma ampliação conceptual de lugar como experiência de mundo vivido, de afetividade, lugar como parte do todo. Sem esse procedimento, somos "impossibilitados de desmembrar o todo através de um processo de análise, para reconstruí-lo depois através de um processo de síntese (MAIA; ALVES, 2009, [s.p.])". Assim, um diálogo com outras áreas do saber é fundamental: Geografia Cultural e Humanista.

Se vamos partir da concepção de ampliar a noção de lugar para uma categoria do conhecimento toponomástico, justifica-se também a ampliação para o estudo das relações que o homem estabelece com o lugar, como parte integrante de um todo maior. A totalidade é o espaço geográfico. A episteme Geográfica se consolidou como uma disciplina que tem como objeto de estudo as relações entre o homem e o meio (natureza), concentrando-se no estudo do espaço geográfico. 


\section{Lugar na perspectiva da Geografia Cultural, Humanista e Toponímica}

A relação homem e meio se estabelece através do espaço. Para Sueretegaray (2001), é preciso pensar o espaço geográfico como um todo uno e múltiplo, aberto a diversas conexões que se expressam por meio dos diferentes conceitos já apresentados. Esses, ao mesmo tempo em que separam visões, também as unem. Para melhor explicitar o pensamento, a autora apresenta as categorias operacionais do espaço.

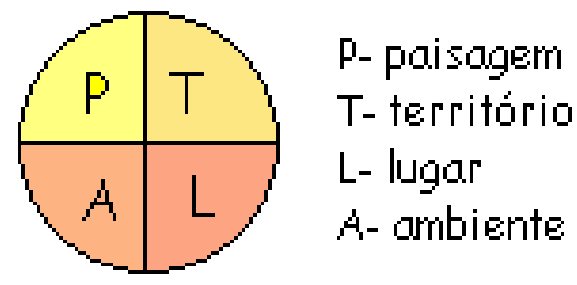

FIGURE 1 - Categorias operacionais do espaço (SUERTEGARAY, 2001)

Para a autora, essa representação é proposta com o intuito de expressar a concepção de que o espaço geográfico pode ser lido a partir das categorias paisagem, ${ }^{3}$ território, ${ }^{4}$ lugar,${ }^{5}$ ambiente; ${ }^{6}$ sem desconsiderar que cada uma dessas dimensões está contida em todas as demais. A

\footnotetext{
${ }^{3}$ De uma perspectiva clássica, os geógrafos perceberam a paisagem como a expressão materializada das relações do homem com a natureza num espaço circunscrito. Para muitos, o limite da paisagem atrelava-se à possibilidade visual. (SUERETEGARAY, 2001) (grifo nosso). ${ }^{4}$ Sob o conceito de território, tratamos o espaço geográfico a partir de uma concepção que privilegia o político ou a dominação-apropriação. Historicamente, o território na Geografia foi pensado, definido e delimitado a partir de relações de poder. (SUERETEGARAY, 2001) (grifo nosso).

${ }^{5}$ Lugar constitui a dimensão da existência que se manifesta através "de um cotidiano compartido entre as mais diversas pessoas, firmas, instituições-cooperação e conflito são a base da vida em comum. (SANTOS, 1997 apud SUERETEGARAY, 2001) (grifo nosso).

${ }^{6}$ Geografia tem pensado o ambiente diferentemente da Ecologia, nele o homem se inclui não como ser naturalizado, mas como um ser social produto e produtor de várias tensões ambientais. (SUERETEGARAY, 2001) (grifo nosso).
} 
contiguidade é a relação que imbrica e permeia paisagem, território, lugar e ambiente. Embora, Suertegaray (2001) atente-se para o fato de que uma frutífera articulação com as conexões imbricadas pode gerar a um reducionismo da noção de espaço.

Segundo Azevedo (2002, p. 64), na busca por um caminho metodológico, pensamos o todo nas partes e as partes no todo, numa perspectiva holográfica, como um caleidoscópio. O todo e as partes estão ali, mas a cada vez que se olha apresentam-se com um desenho que é sempre inovado. O todo é mais do que a soma das partes, porque possui mais propriedades e qualidades do que cada parte separada. Mas, ao mesmo tempo, é também menos, ao constituir-se impõe limites às partes, que perdem a liberdade.

Quando situamos a relação todo/parte e parte/todo, estamos caminhando para uma concepção humanística, a qual estabelece entre espaço e lugar uma relação de "penumbra e claridade - [...] corporificados a partir de experiências, ambiguidade e valores humanos, que manifestam níveis distintos de especificidades" (MELLO, 2011, p. 7), concepção que se preocupa com os espaços e lugares dos homens. O que ele conhece, vive, conota aconchego, afetividade, proximidade; é o lugar por excelência, é o vivido, corporificado. O que se desconhece torna-se mistério, intimidação, ameaça e desesperança. Portanto, existir pressupõe a ideia de ter um lugar, seja uma casa, um hotel, uma rua, um viaduto, um bairro, enfim, o homem necessita de um lugar, um "ninho" para viver. É daí que ele estabelece seus vínculos afetivos, sociais, culturais, guarda seus mistérios, refúgio, confinamento, é o seu cosmo.

Tuan (1983, p. 3) apud Mello (2011, p. 9) inicia sua obra com a frase "Não há lugar como o lar". Mas, o que é o lar? Em seguida, dá a resposta: a velha casa, o bairro, a cidade ou a pátria. Na simplicidade da resposta uma teia complexa e simbólica sustenta sua afirmação: é a gênese da alma dos lugares que estabelece os laços de afetividade e de convivência entre os homens que ocupam os espaços. Tuan, (1980) apud Mello (2011, p.10) diz que, por símbolo, entende-se a parte representativa do todo. Ou seja: o sentimento de lugar se apropria, simbolicamente, das faixadas, das calçadas, dos letreiros, das cores, do cheiro. Qualquer ruptura que ocorra em um desses elementos causa perda, protestos.

É o que acontece quando o nome de um lugar é alterado. Tem-se, nesse caso, um sentimento de dor, abandono, aflição. O sentimento de identidade é afetado profundamente pelo vazio da perda, da desesperança, 
da angústia. Não se sabe o que vem pela frente, o que era sólido, firme e resistente, torna-se líquido, dilui, entra pelas frestas. E daí o caminho, outrora conhecido, vivido e experienciado passa a ser uma incógnita. O que era luz vive a penumbra; o que era afeição desanda ao mistério. Mas a essência permanece, pois ela constitui a natureza permanente e universal de uma coisa. Lembrando que, embora o nome tenha sofrido uma alteração, ao deixar de existir, isso não acontece com a essência do lugar, ela permanece no íntimo e na alma de cada morador. Os vínculos estabelecidos, em tempos passados, evocam sentimento de posse, são elementos de significado.

Segundo Mello (2011, p. 10)

Esta questão de posse, defesa e significado remonta à noção fenomenológica ${ }^{7}$ do mundo vivido trabalho contemplando indissociavelmente os pertences privados ou públicos, parentes ou amigos, conhecidos e a base territorial intrinsecamente imbricados e fazendo parte do acervo íntimo do indivíduo ou grupo social. Em outras palavras, consoante a alma dos lugares.

Nossas experiências partem dos lugares, diversos são os elementos que agregam laços de afetividade, os quais formam uma teia complexa e simbólica de experiências: a praça, a rua, as calcadas, o movimento contínuo de ir e vir das pessoas, dos carros. Esses, ainda que efêmeros e sofrendo mudanças, podem eternizar-se no íntimo das pessoas. Para Mello (2011, p. 07), “o conceito lugar, baseado nos princípios da

\footnotetext{
7 "[...] a fenomenologia não é acessível senão a um método fenomenológico" (MERLEAUPONTY, 1945, p. II apud PERIUS, 2012, p. 138) que não é uma doutrina, um saber, um conjunto de teses ou ideias, porém um projeto incoativo, “[...] laborioso como a obra de Balzac, Proust, Valéry ou Cézanne.” (MERLEAU-PONTY, 1945, p. XVI apud PERIUS, 2012, p. 138), pois a fenomenologia não é neutra em relação a suas respostas e conceitos, mas subtende a si mesma enquanto possibilidade de pergunta por um campo sobre qual está inclinada e suspendida como questão de fato. Se é laboriosa como a obra do escritor, e condenada a recomeçar indefinidamente em torno de si mesma, não é por conter um mistério qualquer, mas conter a exigência de surpreender o nascimento de si mesma, através de uma interrogação contínua que não ultrapassa o seu objeto, mas se compreende através dele, e assim o exige, toda vez que interrogar o que ela é. (PERIUS, 2012, p. 139)
} 
fenomenologia ${ }^{8}$ com a noção do mundo vivido, confunde-se com a própria trajetória da geografia humanista, sendo considerado lar, por excelência, no qual cria, projeta, vive, ama e atua".

No entender de Tuan (2012, p. 135), o sentimento e o seu objeto são, muitas vezes, inseparáveis. Aqui ele faz referência à topofilia, cujo neologismo pode ser definido, em sentido amplo, como incluindo todos os laços afetivos dos seres humanos com o meio ambiente ${ }^{9}$ material. Mas e os sentimentos que temos com o lugar? O autor responde que os sentimentos que temos com lugar, os laços criados e fortalecidos com o tempo, por ser o lar, é o locus de reminiscências e o meio de se ganhar a vida.

Quando evocamos as reminiscências, a memória é ativada, uma vez que produz afeição, lembranças de um tempo que não volta mais. $\mathrm{E}$ o nome de lugar passa a ser sua extensão, seu passado, suas memórias, e qualquer modificação é sinônimo de privação de seu valor enquanto homem. Ao alterar o nome, por exemplo, o homem sente-se despido de um invólucro, e devido ao seu sentimento de pertencimento, percebe-se abalado diante das perplexidades do mundo.

A memória, nos estudos nomes de lugares, constitui-se em elemento essencial para o conhecimento e a interpretação do espaço/ lugar referencial ou imaginário. De acordo com o dicionário Etimológico da Língua Portuguesa de Cunha (2010, p. 419), memória significa "lembrança, reminiscência, vem do latim mĕmŏria, de memor -ŏris "que se lembra". Os diferentes interlocutores, como membros de uma determinada comunidade linguística, quer como falantes, quer como ouvintes, recorrem à memória de sua comunidade e dela fazem uso, na interação, para produzir atos de fala e interpretá-los a todo instante. Com efeito, enquanto fenômeno que se produz no interior de uma comunidade, configura-se como memória coletiva. Segundo Merleau-Ponty (1999), sendo a memória vestígio perceptivo, ela não se exprime necessariamente

\footnotetext{
${ }^{8}$ Fenomenologia: o fenómeno (o que aparece à consciência) é o objeto de intuição ou de conhecimento imediato, ao mesmo tempo, é a manifestação da essência. (CLÉMENT et al, 1994, p. 149),

${ }^{9}$ Gonçalves (1989) apud Suertegaray (2001), em sua crítica ao conceito de meio ambiente, propõe uma visão de ambiente por inteiro, ou seja, considerá-lo nas suas múltiplas facetas. Não sendo mais possível conceber ambiente como equivalente a natural. $\mathrm{O}$ ambiente, por inteiro como se refere, implica em privilegiar o homem como sujeito das transformações, sem negar as tensões sob as mais diferentes dimensões.
} 
de forma consciente, uma vez que também é memória daquilo que se esquece e que se manifesta no corpo.

Como elemento integrante de uma língua, o léxico, por exemplo, pode atualizar a partir da combinatória da seleção dos fatos da memória coletiva com os diferentes modos de apreensão do espaço/lugar referencial ou imaginário, variando de comunidade para comunidade. Dick (1990, p. 20) refere-se ao topônimo como um verdadeiro fóssil linguístico, expressão emprestada do geógrafo francês do século XIX, Jean Brunhes, que o considerava como "um fóssil da geografia humana". Para a autora,

[Os topônimos], ao lado de uma função identificadora, guardam, em sua estrutura imanente, uma significação precisa, muitas vezes não mais transparente em virtude da opacidade que esses nomes adquirem, ao se distanciarem de suas condicionantes tempo-espaciais. (DICK, 1990, p. 19).

De fato, alguns autores definem os topônimos como elementos de característica fossilizada pelo valor que se revestem como fonte de conhecimento histórico, cultural e social quanto à denominação de um lugar, testemunhados pelo grupo que habitou o sítio, seja de caráter temporário ou permanente. É o caso de Carvalhinhos (2002) que também compara um topônimo a fóssil descoberto pela paleontologia:

o maior ou menor grau de "descoberta" ou "achado valioso" depende da antiguidade do nome cristalizado em determinado momento da oralidade (termo utilizado: cristalização); Rostaing denominava fossilização o fenômeno. Descreve-se, assim, a tendência conservadora do topônimo (CARVALHINHOS, 2002, p. 173).

Os topônimos, nesse caso, como fato sociais e culturais, servem como documentação para outras disciplinas: História, Geografia humana e cultural, Arqueologia e Antropologia. Tuan (2012, p. 144) chama a atenção para a consciência do passado, como um elemento admirável e respeitável pelo lugar.

A retórica patriótica sempre tem dado ênfase às raízes de um povo. Para intensificar a lealdade se torna a história visível com monumentos na paisagem, e as batalhas 
passadas são lembradas na crença de que o sangue dos heróis santificou o solo. Os povos analfabetos podem estar profundamente afeiçoados ao seu lugar de origem. Eles podem não ter o senso ocidental moderno, mas quando procuram explicar a sua lealdade para com o lugar, ou apontam os laços com a natureza (o tema mãe-terra), ou recorrem à história. (TUAN, 2012, p. 144)

Sob perspectiva geográfico-cultural, Claval (2001) considera a denominação de lugares como tomada de posse do espaço, afirmando que todos os lugares habitados e um grande número de sítios característicos na superfície da Terra têm nomes - frequentemente há muito tempo. A Toponímia é uma herança preciosa das culturas passadas. Batizar as costas e as baías das regiões litorâneas foi a primeira tarefa dos descobridores. "O batismo do espaço e de todos os pontos importantes não é feito somente para ajudar uns aos outros a se referenciar. Trata-se de uma verdadeira tomada de posse (simbólica ou real) do espaço (CLAVAL, 2001, p.189)".

A título de exemplificação, temos o nome Morro de São João, uma comunidade remanescente quilombola do estado do Tocantins. Conforme relatos da tradição oral, sua formação histórica é originada da ruptura dos escravos com as estruturas econômicas sociais do passado colonial, representadas pela fazenda, constituindo-se um dos grupos de população rural negra mais antigos da região. Para o grupo, o presente não se interpreta por si mesmo, mas está envolvido dentro de um discurso de valores "entre tempos". Assim, todas as coisas que existem agora, e através das quais as pessoas se enfrentam, são definidas a partir de um confronto com tempos anteriores, e pelas formas como os mesmos tipos de sujeitos e relações existiram dentro de cada um deles. A população explica a sua sociedade pelo desdobramento da mesma em duas etapas: passado e presente. Há uma época distante que quase não alcança a biografia de qualquer membro vivo da comunidade. Esse é o período que eles costumam chamar de "tempo antigo". Finalmente, o "tempo novo" é o tempo definido por eles como sendo de "benefícios", em alusão às políticas públicas, usufruídas dentro do programa "Brasil Quilombola". ${ }^{10}$

\footnotetext{
${ }^{10}$ O Programa Brasil Quilombola foi lançado em 12 de março de 2004, com o objetivo de consolidar os marcos da política de Estado para as áreas quilombolas. Informações disponíveis em: <http://www.seppir.gov.br/comunidades-tradicionais/programa-brasil-quilombola >. Acesso em: 12 de novembro de 2014.
} 
O lugar se particulariza a partir de visões subjetivas atreladas a percepções emotivas. As apreensões do lugar são derivadas da realidade circundante.

Retomando o pensamento de Tuan, o qual associa sentimento com lugar, o autor assinala que "as imagens mudam à medida que as pessoas adquirem novos interesses e poder, mas continuam a surgir do meio ambiente" (TUAN, 2012, p. 170). Ao mirar seu ambiente circundante, o homem consegue traduzir suas experiências ao partir de uma realidade concreta: o aspecto físico, humano, sensorial. É essa totalidade que constitui a identidade do grupo, conferindo-lhe uma situação de luta ao manter fatos culturais que tornaram a comunidade símbolo de resistência.

É com esse exemplo que retomamos a discussão inicial de ampliar conceptualmente lugar e elevá-lo à categoria em Toponímia. Nossa proposta, como base nas discussões já apresentadas, é partirmos do conceito de lugar como noção de sentimento de pertencimento, afetividade, mundo vivido e experienciado. Tuan (2012, p.135) fala em amor humano ou topofília: "laços afetivos dos seres humanos com o meio ambiente material". Para tal proposição, ainda que não seja nosso objetivo aprofundar em questões vinculadas à Geografia Humanista e Cultural, nem tampouco à Fenomenologia Existencialista, é fundamental, como "pano de fundo", que discutamos a partir dessas áreas do saber. Quando nos referimos a "sentimento de pertencimento e afetividade", entendemos "pertencer" como fazer parte de alguma coisa, ter relação com; e "afeiçoar", estima, consideração. O sentimento de pertencimento implica, portanto, manter vínculo com um determinado lugar, grupo, história. E a afeição se vale do sentimento de apego por alguém ou algo, afeiçoamento, que também pode ser entendido como relação, conexão. Segundo Tuan ${ }^{11}$ (2012, p. 136), "os pertences de uma pessoa são uma extensão de sua personalidade; ser privado deles é diminuir seu valor como ser humano, na sua própria estimação". O caso de Morro de São João revela o quão a consciência do passado é um elemento importante

\footnotetext{
${ }^{11}$ Holzer (2003, p. 121), ao discutir a bibliografia de Tuan (1975), diz que em Place: an experential perspective, o autor "caracteriza o lugar a partir da experiência. O lugar, então, era avaliado como lar, em suas diversas escalas: o próprio lar, a vizinhança, a cidade, a região (o qual atribuía características semelhantes à da vizinhança), e o estado-nação. Mais tarde, com a publicação de Space and Place: the perspective of experience, Tuan (1983) consolida suas investigações a respeito de lugar. (TUAN, 1975 apud HOLZER, 2003, p. 121).
} 
nos vínculos que a comunidade estabeleceu com o lugar, com o mundo vivido e experienciado. Ao assinalarmos que uma coisa é, aceitamos a sua existência; e ao dizermos o que ela é, definimos a sua essência. De acordo com Rosental e Iudin (1972) “[...] A essência está relacionada com a consciência e com o pensamento". (p. 92). “[...] A essência não existe fora das coisas, mas nelas e através delas, como a sua propriedade geral, como a sua lei (ROSENTAL; IUDIN, 1972, p. 93).” A busca pela essência é a busca de sua própria natureza.

Segundo Pereira (2013), perceber o mundo e a existência do sujeito são fios de uma mesma meada, e o lugar, por sua vez, está encarnado no sujeito posto que a existência é espacial. "O mundo vivido é o lugar onde habitam os homens, e compreendê-lo é uma tarefa que exige um reaprender constante, um reapreender a ver o mundo e um reaprender a ver o lugar" (PEREIRA, 2013, p. 138).

Para Clémente et al (1994, p. 130)

Não existe, para o existencialismo, um sentido anterior à existência, nem qualquer sentido que não seja o que $o$ homem lhe dá. É o que traduz a formula de Sartre: $<$ A existência precede a essência> (CLÉMENT et al, 1994, p. 140). (grifos dos autores) [...] O existencialismo pretende afirmar que o Homem, por assim dizer, se cria a si próprio, pelos seus actos e escolhas (CLÉMENT et al, 1994, p. 130).

E assim, o conhecimento humano vai se apropriando lentamente e gradualmente da essência do mundo objetivo, e, por conseguinte, no seu desenvolvimento, nele se aprofunda. É pensar em como o homem se vê no mundo, suas percepções, atitudes e cosmovisão, como ele se relaciona e estabelece vínculos com o outro e com o próprio mundo circundante. O lugar emana luz, personalidade, existe um "sentido do lugar" (TUAN, 1979 apud HOLZER, 2003, p. 120). O lugar é visto como expressão de conteúdo estético e de sentidos. Ou seja: os sentimentos que o lugar suscita no homem, visual, olfativo, paladar e tato, os quais exigem uma interlocução, uma interação, com o ambiente que o envolve: interação aqui é partilhar sentidos, experiências com o outro. "A comunicação tem de ser compreendida a partir da estrutura do ser-aí1 ${ }^{12}$ como ser com

\footnotetext{
${ }^{12} \mathrm{O}$ ser-aí é interpretado como o ser que tem relações com o mundo.
} 
o outro" (HEIDEGGER, 1988b, p. 362-363 apud DUARTE, 2005), p. 136.), de tal modo que a "análise ontológica da linguagem tem de ser, simultaneamente, uma análise da co-existência, do ser um com o ser outro. (DUARTE, 2005, p. 136)". O mundo não é aquele que eu penso, mas aquele que eu vivo, estar aberto ao mundo é comunicar-se com o mundo.

Para Milton Santos (2000, p. 269), a ideia de interação equivale a uma "verdadeira negociación social",

"Comunicar", nos recuerda H. Laborit (1987, p. 38), "significa etimologicamente poner en común". Esse processo, en el cual entran en juego diversas interpretaciones de lo existente, es decir, de las situaciones objetivas, resulta de una verdadera negociación social, de la que participan preocupaciones pragmáticas y valores simbólicos, "puntos de vista más o menos compartidos". (SANTOS, 2000, p. 269) $)^{13}$

O autor chama atenção para a ideia de que relacionar-se com o outro implica a ideia de mundo. E o mundo adquire sentido no seio das relações de familiaridade e reciprocidade ao produzirem o sentimento de alteridade. Para finalizar, Santos (2000, p. 268) trata lugar com a acepção de existência de um mundo vivido. "Cada lugar es, a su manera, el mundo". Para ele, existência é sinônimo de liberdade, no sentido da perspectiva filosófica do existencialismo. ${ }^{14}$ É no lugar que a essência ${ }^{15}$ se torna existência.

13 “Comunicar", nos lembra H. Laborit (1987, p. 38, apud SANTOS, 2000), "significa etimologicamente colocar em comum". Esse processo, no qual entram diversos jogos de interpretações do existente, ou seja, das situações objetivas, resulta de uma verdadeira negociação social, da qual participam questões pragmáticas e valores simbólicos, "pontos de vistas mais ou menos divididos". (Tradução nossa)

${ }^{14}$ Segundo Clemént et al (1994, p. 139 e 140), "do ponto de vista do existencialismo, deve-se partir da unidade sujeito e objecto. Esta unidade acha-se encarnada na <existência>, quer dizer, em certa realidade irracional. Ao dizermos que uma coisa é, admitimos a sua existência; quando dizemos o que ela é, definimos a sua essência. A existência repercute no ser, não enquanto essência, mas no ser que se opõe ao nada. Existir é, pois, <ex-sistir>, no sentido de si próprio, de uma abertura do ser. $<$ A essência do homem é a existência: escreve Heidegger".

15 "Etim.: latim essentia, de esse, "ser", tradução do grego ousia. Sentido comum: o que a natureza faz uma coisa ou de um ser. Filosofia: 1. Opondo-se a acidente, aquilo que constitui a natureza 
Santos, ao recordar-se do filósofo Michel Serres, ${ }^{16}$ remete lugar ao estado de reflexão a respeito de nossa relação com o mundo. Um mundo cada vez mais globalizado, fluido. É a nova ordem mundial. E apropriação da tecnologia torna os homens clandestinos, despaisados (estrangeiros), sem fronteiras. E o lugar pode passar a ter uma outra dimensão de "existência de um mundo vivido".

Segundo Pereira (2013, p. 90), vivemos e nos relacionamos com um mundo cheio de significados, e no debate sobre o lugar está imbricado a reflexão sobre o mundo, uma vez que construir o lugar é também construir a nós mesmos. "Compreender um lugar e o nome que este carrega consiste em traduzir a emoção bruta que esse encontro faz nascer e crescer em nós, em outra linguagem possuidora de um poder de elucidação. Compreender é interpretar um sentido imediatamente percebido porque pertence ao próprio lugar" (BESSE, 2011, p. 130 apud PEREIRA, 2013, p. 90).

Retomando, portanto, nossa proposta inicial de ampliação conceptual de lugar, com base em questões teóricas e metodológicas da Geografia Cultural e Humanista, reconhecemos lugar como uma dimensão de categoria analítica: motivacional, geográfica, histórica, linguística, ideológica, sociocultural, identitária. E sua extensão semântica se dá no plano de compreendê-lo como sentimento de pertencimento, afetividade, mundo vivido e experienciado na relação que se estabelece entre o denominador e o designatum.

\section{Caminhos a ainda trilhar}

Desde o início, uma questão dominou o cenário da investigação: qual é o status ou posição que lugar ocupa na área da Toponímia, ou seja, nomes de lugares? No nosso entender, lugar é mais que uma referência locacional. Não faz sentido algum estudar o lugar partindo apenas da localização, o lócus, recorte que se faz no/do espaço, espaço esse entendido como transformação social. Mas adiantamos que não foi nossa

\footnotetext{
permanente de um ser, independentemente do que lhe acontece; neste sentido, próximo de "substância". 2. Opondo-se à existência, o que é um ser, independentemente do facto de existir; neste sentido, próximo de "conceito". (CLÉMENT et al, 1994, p. 127 e 128).

${ }^{16}$ Michel Serres apud Santos (2000, p. 267) em uma entrevista a Bernardo Carvalho, Folha de São Paulo, 21 de abril de 1990.
} 
pretensão alterar ou mudar, em sua essência, o conceito de Toponímia como o estudo do nome de lugar. A ideia vincula-se mais na perspectiva de uma ampliação conceptual no que se refere a lugar em Toponímia. A intenção foi construir uma proposição conceitual e metodológica que pudesse permitir elevar lugar à noção de categoria nessa área. Para tal empreitada, a contribuição do constructo teórico e metodológico da Geografia Cultural e Humanista foi fundamental.

Partimos, então, do princípio que lugar é mais que o espaço apreendido e ocupado, localização referenciada, nomeada. Seguindo tal premissa, assinalamos que o conhecimento que abrange este estudo possibilita algo a mais, como o entendimento ou apreensão das relações (motivações) que são estabelecidas entre o homem e o nome de lugar. É neste sentido que a Toponímia, como disciplina vinculada à Onomástica, sugere um movimento de aglutinação de múltiplos aspectos sóciohistóricos, culturais, geográficos e linguísticos, dentre outros. Portanto, ao nomear um recorte cultural, o denominador vale de elementos descritivos de caráter objetivo (características geomorfológicas, fauna, flora etc) ou subjetivo (emoções, cores, cheiro etc). Qualquer elemento pode desencadear um vínculo que, na nossa concepção, é permeado de afetividade. O lugar passa a ter "alma", é corporificado e materializado no ato da denominação.

$\mathrm{O}$ alçamento, enquanto categoria central, deu-se com uma discussão prévia das categorias espaço, território, paisagem e lugar, com base em Sueretegaray (2001) e Santos (2000). Daí o conceito em uma dimensão de categoria analítica: motivacional, histórica, linguística, ideológica, social, identitária.

Considerando as discussões da Geografia Cultural e Humanista, acreditamos na ampliação conceptual de lugar como noção de sentimento de pertencimento, afetividade, mundo vivido e experienciado. Nesse sentido, percebemos o nome de lugar como um patrimônio linguístico e cultural, testemunho de uma comunidade. Materializado e corporificado, o nome é um produto e o reflexo social e cultural da cosmovisão de um grupo. Citando Fonseca (1997, p. 18), como referentes de uma realidade nomeada, objetos de uma cultura, os topônimos podem ser concebidos, de acordo como um centro político-social a partir do qual se organiza culturalmente um espaço geográfico, sendo a nomeação de entidades geográficas uma manifestação específica do poder organizador que um grupo exerce sobre a paisagem geográfica. 


\section{Referências}

ANDRADE, Karylleila dos Santos. Os nomes de lugares em rede: um estudo com foco na Interdisciplinaridade. Revista Eletrônica de Linguística Domínios de Linguagem, v. 6, n. 1, p. 205-225, mar.-jun 2012. ANDRADE, Karylleila dos Santos. Atlas toponímico de origem indígena do estado do Tocantins: Atito. Goiânia: Ed. da PUC Goiás, 2010.

AZEVEDO, J. G. A tessitura do conhecimento em redes. In: OLIVEIRA, I. B.; ALVES, N. (Org.). Pesquisa no/do cotidiano das escolas: sobre redes de saberes. 2. ed. Rio de Janeiro: DP\&A, 2002. 157p.

BOEMER, Magali Roseira. A condução de estudos segundo a metodologia de investigação fenomenológica. Rev. Latino-am. de Enfermagem, Ribeirão Preto, v. 2, n. 1, p. 83-94, jan. de 1994. Disponível em: <http:// ftp.unisc.br/portal/upload/com_arquivo/1350494711.pdf>. Acesso em: 16 de out. de 2014.

CARVALHINHOS, Patrícia de Jesus. Onomástica e Lexicologia: o léxico toponímico com catalisador e fundo de memória. Estudo de caso: os sociotopônimos de Aveiro (Portugal). Revista USP, São Paulo, n. 56, p. 172-179, dez.-fev. 2002.

CHAUÍ, Marilena. Experiência do pensamento. Ensaios sobre a obra de Merleau-Ponty. 1. ed. São Paulo: Martins Fontes, 2002.

CLAVAL, Paul. A Geografia Cultural. 2. ed. Florianópolis: Ed. UFSC, 2001.

CLEMENT et al. Dicionário prático de filosofia. Terramar: Lisboa, 1994.

CUNHA, Antônio Geraldo da. Dicionário etimológico da língua portuguesa. 4. ed. Revista pela nova ortografia. Rio de Janeiro: Lexicon, 2010.

DICK, Maria Vicentina de Paula do Amaral. Toponímia e antroponímia no Brasil: Coletânea de estudos. 2. ed. São Paulo: Serviço de Artes Gráficas da FFLCH/USP, 1990.

DICK, Maria Vicentina de Paula do Amaral. Etnia e etnicidade. Um novo modo de nomear. Projeto ATESP/ATB. In: ISQUERDO, Aparecida Negri; FINATTO, Maria José Bocorny. As Ciências do léxico. v. IV. Campo Grande: Ed. UFMS, 2008. p.177-198. 
DICK, Maria Vicentina de Paula do Amaral. A toponímia como meio de investigação linguística e antropocultural. In: ISQUERDO, Aparecida Negri (org). Estudos geolinguísticos e dialetais sobre o português. Campo Grande: Ed. UFMS, 2008a. p. 215-231.

DUARTE, André. Heidegger e a linguagem: do acolhimento do ser ao acolhimento do outro. Nat. hum. [online]. v.7, n.1, p. 129-158, 2005. Disponível em: $<$ http://pepsic.bvsalud.org/pdf/nh/v7n1/v7n1a04.pdf $>$. Acesso em: 5 nov. 2014.

FONSECA, Gustavo Solis. La gente pasa, los nombres quedan... Introduccíon en la toponímia. Lengua e Sociedad: Lima, 1997.

HOLZER, Werther. O conceito de lugar na geografia cultural-humanista: uma contribuição para a geografia contemporânea. GEOgraphia, ano V, n. 10, p. 113-123, 2003. Disponível em: <http://www.uff.br/geographia/>. Acesso em: 24 out. 2014.

ISQUERDO, Maria Aparecida Negri; SEABRA, Maria Cândida Trindade Costa de. A trilha dos "buritis" no vocabulário onomástico-toponímico: um estudo na toponímia de Minas Gerais e de Mato Grosso do Sul. In: BARROS, Lídia Almeida; ISQUERDO, Maria Aparecida Negri (Org.). O léxico em foco. São Paulo: Cultura Acadêmica, 2010.

KANTOR, Íris. Usos diplomáticos da ilha-Brasil: polêmicas cartográficas e historiográficas. Varia História, Belo Horizonte, v. 23, n. 37, p. 70-80, jan.-jun. 2007.

LAKATOS, Eva. M; MARCONI, Marina A. Metodologia Científica. São Paulo: Editora Atlas, 1991.

MAIA, Adriano Correa; ALVES, Flamorian Dutra. Categoria e epistemologia: reflexões teórico-metodológicas na ciência geográfica. Encontro de Grupos de Pesquisa em Educação ANAIS V e Território, novembro de 2009.

MELLO, João Baptista Ferreira de. A humanística perspectiva do espaço e do lugar. Revista ACTA Geográfica, ano v, n. 9, p. 7-14, jan.-jun. 2011. Disponível em: <http://revista.ufrr.br/index.php/actageo/article/ view/429>. Acesso em: 24 out. 2014.

MERLEAU-PONTY, Maurice. Fenomenologia da percepção. Trad. Carlos Alberto Ribeiro de Moura. 2. ed. São Paulo: Martins Fontes, 1999. 
PEREIRA, Carolina Machado Rocha Busch. Geografias de mundo reveladas nas canções de Chico Buarque. 2013. 150f. Tese (Doutorado em Geografia) - Faculdade de Filosofia, Letras e Ciências Humanas, Departamento de Geografia, Universidade de São Paulo, São Paulo, 2013.

PERIUS, Cristiano. A definição da fenomenologia: Merleau-Ponty leitor de Husserl. Trans/Form/Ação, Marília, v. 35, n. 1, p. 137-146, jan.-abr. 2012. Disponível em: $<$ http://www2.marilia.unesp.br/revistas $>$. Acesso em: 24 out. 2014.

ROSENTAL, M. M.; IUDIN, P. F. Dicionário filosófico. 3. ed. v. ABC. Editorial Estampa: Lisboa, 1972.

SANTOS, Milton. La naturaleza del espacio. Técnica y tiempo - razón y emoción. Barcelona: Ariel Geografía, 2000.

SARTRE, Jean-Paul. O ser e o nada. Ensaios de ontologia fenomenológica. 7. ed. Petrópolis/RJ: Vozes, 1997.

SUERTEGARAY, Dirce Maria Antunes. Espaço geográfico uno e múltiplo. Scripta Nova Revista Electrónica de Geografía y Ciencias Sociales, Barcelona, Universidad de Barcelona, n. 93, 15 jul. 2001. Disponível em: < http://www.ub.edu/geocrit/sn-96.htm>. Acesso em: 23 out. 2014.

TODOROV, Tzvetan. A conquista da América. São Paulo: Martins Fontes, 1983.

TUAN, Yi-Fu. Topofilia. Um estudo da percepção, atitudes e valores do meio ambiente. Eduel: Londrina, 2012.

ULLMANN, S. Semântica: uma introdução ao significado. 4. ed. Lisboa: Fundação Calouste Gulbenkian, 1964. 